\title{
Prostate Specific Antigen in a Community-Based Sample of Men Without Prostate Cancer: Correlations With Prostate Volume, Age, Body Mass Index, and Symptoms of Prostatism
}

\author{
J.L.H. Ruud Bosch, Wim C.J. Hop, Chris H. Bangma, Wim J. Kirkels, and \\ Fritz H. Schröder \\ Departments of Urology (I.L.H.R.B., C.H.B., W.J.K., F.H.S.), and Epidemiology and \\ Biostatics (W.C.J.H.), Erasmus University and Academic Hospital, Rotterdam, \\ The Netherlands
}

\begin{abstract}
The correlation between both prostate specific antigen levels (PSA) and prostate specific antigen density (PSAD) and age, prostate volume parameters, body mass index, and the International Prostate Symptom Score (IPSS) were studied in a communitybased population. A sample of 502 men aged 55 through 74 years was evaluated, excluding those with a serum PSA above $10 \mathrm{ng} / \mathrm{ml}$, those with biopsy proven prostate cancer, and those who had previously undergone a prostate operation.

PSA and PSAD did not correlate with the body mass index. Weak correlations were found between PSA and age $(r=0.25 ; P<0.001)$, PSAD and age $(r=0.17 ; P<0.001)$ and between PSA and the total prostate volume $(r=0.58 ; P<0.001)$. PSA did not correlate independently with age after adjustment for volume $(P=0.22)$. The finding that PSAD correlates with age $(\mathrm{r}=0.17 ; P<0.001)$ is partly explained by the incomplete volume adjustment of PSAD which is proved by the positive correlation between PSAD and prostate volume $(\mathrm{r}=$ $0.26 ; P<0.001)$.

In the main target age-range for prostate cancer screening there is a poor basis for the use of age-specific reference values or volume adjustment for PSA levels in order to increase the clinical usefulness of this serum marker. Comparison of the results of the present study and studies conducted in others regions shows that there may be significant differences in PSA values per age stratum. Further studies are needed to clarify the reasons for these differences. (c) 1995 Wiley-Liss, Inc.
\end{abstract}

KEY WORDS: benign prostatic hyperplasia, prostatic hypertrophy, prostatic neoplasms, community medicine

\section{INTRODUCTION}

Prostate specific antigen (PSA) is a serine protease produced by the epithelial cells of the prostate [1]. The upper range of normal for the monoclonal prostate specific antigen level as recommended by the manufacturer is $4 \mathrm{ng} / \mathrm{ml}$ (Hybritech, San Diego, CA). However, it has been shown that benign prostatic hyperplasia (BPH) can be associated with elevated prostate specific antigen levels in $21-53 \%$ of the patients [2-5]. Although Stamey et al. [6] have shown that the serum PSA level is elevated by $0.310 \pm 0.25$ $\mathrm{ng} / \mathrm{ml}$ per $\mathrm{gm}$ of BPH tissue (polyclonal Yang-assay) others $[7,8]$ have not been able to find a clear relationship between serum PSA levels and the amount of hyperplastic BPH tissue. In spite of the results of the latter studies, attempts have been made to increase the specificity of the PSA assay by prostate volume adjustment $[9,10]$.

Received for publication May 10, 1994; accepted November 8, 1994. Address reprint requests to J.L.H. Ruud Bosch, M.D., Department of Urology, AZR-Dijkzigt, H 1073, Dr. Molewaterplein 40, 3015 GD Rotterdam, The Netherlands. 
Several studies have correlated serum PSA with age and with the total prostate gland volume, as measured by transrectal ultrasound [10-13] in men in whom prostate cancer has been excluded with a reasonable level of certainty. Two of these studies were done in a community-based population $[12,13]$. The men included in the study by Collins et al. [13] were, however, preselected on the basis of the presence of moderate to severe symptoms of prostatism and/or a flow rate below $15 \mathrm{ml} / \mathrm{sec}$. The results of these studies were contradictory as to the aspect of association between serum PSA levels and age.

Kane et al. [10] evaluated 1,695 men with no likelihood of clinically significant prostate cancer between the ages of 55-70 years. These men had no history of prostatic surgery. In this study, a relationship was observed between serum PSA and prostate gland volume but not between age and PSA levels or between symptoms of prostatism and PSA levels independent of gland volume.

Babaian et al. [11] studied 343 self-referred men and 65 physician-referred men because of an abnormal digital rectal examination or transrectal ultrasound, or an elevated serum PSA. These men had a median age of 62 years (range 29-84 years). This study showed significant and independent associations between prostate gland volume and PSA level and between age and PSA level.

Oesterling et al. [12] studied 471 men, aged 40-79 years, who were randomly selected from the community. In this study a relationship was found between PSA and both prostate volume and age.

Collins et al. [13] reported data from a communitybased population of 472 men aged $40-79$ years in whom prostate cancer had been excluded. An independent relation between PSA and both age and prostate volume was observed in this study.

The present evaluation was performed to further clarify the relationship between both PSA and prostate specific antigen density (PSAD) and age, prostate volume, symptoms of prostatism and body mass index in a community-based population of men aged 55-74 years who had no history of prostate surgery and in whom prostate cancer had been excluded with reasonable certainty. It was not the purpose of this study to evaluate the relative importance of PSA, digital rectal examination (DRE), and transrectal ultrasound (TRUS) in a prostate cancer screening program.

\section{MATERIALS AND METHODS}

\section{Study Design}

The community-based data for this study were collected as part of a randomized pilot study of the value of screening versus no-screening for prostate cancer.
TABLE I. Frequency Distribution of Men in Four Consecutive Age-Groups Between 55-74 Years of Age*

\begin{tabular}{lcc}
\hline Age & Total population (\%) & Participants (\%) \\
\hline $55-59$ & 25.8 & 20.9 \\
$60-64$ & 27.9 & 32.0 \\
$65-69$ & 25.6 & 26.1 \\
$70-74$ & 20.7 & 21.0 \\
Total & 100 & 100 \\
\hline
\end{tabular}

*In the general population at the time of creation of the database and in the population of participants at the time they were actually seen for the study.

Based upon the population registry and after taking care of the appropriate legal regulations, the municipal authorities of the City of Rotterdam created a database containing the information necessary to contact all men aged 55 through 74 years of age residing in four different districts of the city. After being invited by mail, 1,186 men agreed to participate in the study. The response rates for the four five-year age-groups between 55 and 74 years, varied between 33 and $36.3 \%$, resulting in a community-based population with a slight overrepresentation of men between 60-64 years of age and a slight underrepresentation of men aged 55-59 years of age (Table I). Part of this effect is explained by aging of the original database between the time of its creation and the time that the men were actually evaluated. An enquiry among participants and non-participants, which was conducted at the end of this study by the department of epidemiology of the community health services of the City of Rotterdam, has shown that participants were not more symptomatic or less symptomatic than non-participants [14].

In all of these men, demographic and other data pertinent to the study, including International Prostate Symptom Score (IPSS) [15], were recorded. A serum PSA ( $\mathrm{ng} / \mathrm{ml}$; Hybritech-assay) determination was used as a pre-screening tool. If the PSA value was above $10 \mathrm{ng} / \mathrm{ml}$, a work-up was advised because of the high probability for prostate cancer [16] and the person was excluded from randomization. This was the case in 30 out of 1,186 men (i.e., $2.5 \%$ of the total study-population; 15 of these 30 men were subsequently diagnosed with prostate cancer).

The remaining men $(\mathrm{N}=1,156)$ were randomized between a screening and a no-screening group. In the latter group, no further studies were done. The 554 men assigned to the screening group were further examined by DRE and TRUS of the prostate.

Height $(\mathrm{H})$ and bodyweight $(\mathrm{BW})$ were recorded and the body mass index was calculated according to 
the formula: BW/ $\mathrm{H}^{2}\left(\mathrm{~kg} / \mathrm{m}^{2}\right)$. An index of $20-25 \mathrm{~kg} / \mathrm{m}^{2}$ is considered to be normal; a value above $25 \mathrm{~kg} / \mathrm{m}^{2}$ indicates overweight. Those who were subsequently found to have prostatic cancer $(\mathrm{N}=10)$, those who had undergone a prostate operation $(\mathrm{N}=39)$, and the few men who refused the transrectal ultrasound examination $(\mathrm{N}=3)$ were excluded from the present evaluation.

A community-based population of 502 persons in whom prostate cancer had been excluded with reasonable certainty and who had not previously undergone a prostate operation was thus established.

\section{Procedures}

Symptoms. The questionaire used is the AUA-7 symptom index [17] which has been adopted by the World Health Organization (WHO) as the international prostate symptom score (IPSS) [15]. According to AUA scoring conventions, the men were grouped in three categories of symptom severity: those with minor symptoms (IPSS 0-7), those who were moderately (IPSS 8-19) and those who were severely (IPSS 20-35) symptomatic [17].

Prostate evaluation. A $7 \mathrm{MHz}$ Bruel and Kjaer multiplane sector scanning probe was used to measure prostate volumes with the transrectal planimetric technique [18]. This involves measuring the surface area of transverse sections taken through the prostate at $5 \mathrm{~mm}$ intervals. The average of two surface areas multiplied by $5 \mathrm{~mm}$ gives the volume for each step, and the cumulative volume allows the total prostatic volume $\left(\mathrm{cm}^{3}\right)$ to be derived. The same technique was used to determine the volume of the central prostate. The reliability of this method in our hands was shown in a previous study of the intraand inter-observer error of the planimetric technique [19]. The transrectal ultrasound image of the prostate does not correspond exactly to McNeal's description [20] of zones. In this study, the relatively hypoechoic central part of the prostate, including adenoma tissue if present, has been defined as the central part of the gland and should not be confused with McNeal's central zone. Its volume is referred to as $\mathrm{VolC}$ as opposed to VolT for total volume of the prostate and VolP (VolT-VolC) for volume of the peripheral part of the prostate. In 47 of the 502 subjects, VolC was not determined separately due to an aselect temporary deviation from the protocol by one of the ultrasonographers.

The PSAD [9] was calculated by dividing the PSA value by the total prostate volume.

If the findings on DRE and/or TRUS were abnormal, prostate biopsies were taken. In case of an elevated PSA level alone (i.e., $4<\mathrm{PSA}<10 \mathrm{ng} / \mathrm{ml}$ ) in combination with normal findings on digital rectal examination and transrectal ultrasound, a biopsy was not performed. Of the original 554 men included in the screening group, $51(9.2 \%)$ had a PSA value between 4 and $10 \mathrm{ng} / \mathrm{ml}$. Prostate biopsies were performed in nine of these 51 men because of abnormal findings on DRE and/or TRUS. Prostate cancer was found in five of these nine men, resulting in a cancer detection rate of $9.8 \%$ in men with a PSA value between 4 and $10 \mathrm{ng} / \mathrm{ml}$. This is lower than the detection rate of $17.7 \%$ as reported by Catalona et al. [16] who used a more liberal biopsy protocol. If a similar detection rate would have been applicable in our population, this would have resulted in the diagnosis of prostate cancer in four additional men, implying that four additional men should have been excluded from the present evaluation. The impact of this number on a total of 502 men is negligible.

\section{Statistical Analysis}

Spearman correlation coefficients ( $r$ ) were used to evaluate the relations between PSA or PSAD and age, IPSS, body mass index, and prostate volume parameters. The Kruskal-Wallis test was used to compare the levels of PSA and PSAD between the three IPSSgroups. If this test indicated significant differences it was followed by Mann-Whitney's test for pairwise comparisons of the median levels. Multivariate analysis was used to evaluate various factors simultaneously. In this latter analysis, serum PSA and prostate volume parameters were analysed after logarithmic transformation to reduce skewness of distributions. This transformation was also used in the calculation of the coefficients of determination $\left(\mathrm{r}^{2}\right)$. The level of statistical significance was set at $P=0.05$ (two-tailed).

\section{RESULTS}

Figure 1 shows the cumulative frequency distribution of the PSA values. Two features of this frequency distribution are noteworthy. Firstly, this distribution is skewed towards the higher PSA values. Secondly, a relatively high percentage of men has a PSA-value of $0.1 \mathrm{ng} / \mathrm{ml}(3 \%)$ or less $(5 \%)$. Seven percent of the men had a PSA value between 4 and $10 \mathrm{ng} / \mathrm{ml}$.

Figure 2 shows the cumulative frequency distribution of the PSAD values. Of the men studied, 95\% had a PSAD below 0.117 and $97.5 \%$ below 0.145 . The median PSAD value of the study population was 0.033 , whereas $30 \%$ of the men had a PSAD value above 0.050 and $7 \%$ above 0.100 .

Descriptive statistics of PSA and PSAD for the different age strata are shown in Table II.

Total prostate volume is positively correlated with 


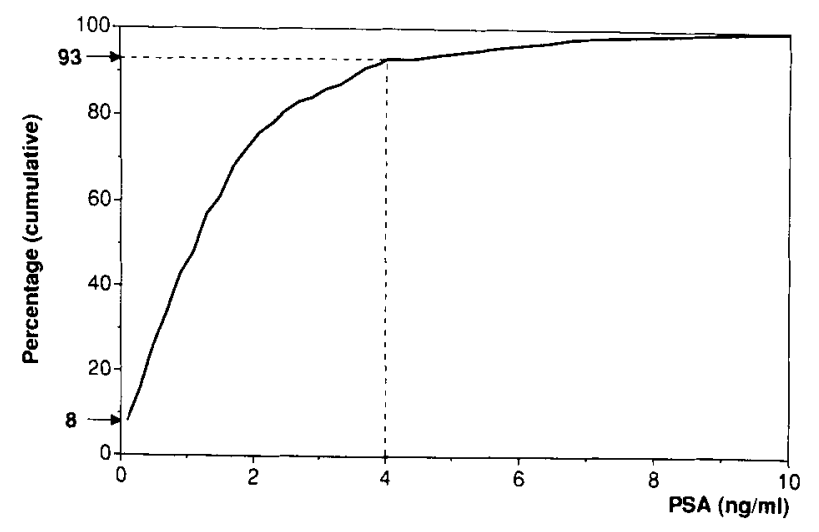

Fig. I. Cumulative frequency distribution of serum PSA values in 502 men without prostate cancer or a previous prostate operation. Men with a serum PSA level above $10 \mathrm{ng} / \mathrm{ml}$ had been excluded.

age $(\mathrm{r}=0.26 ; P<0.001)$. The correlations between PSA and age, IPSS, body mass index, and prostate volume parameters and the correlations between PSAD and age, body mass index, and IPSS are summarized in Table III. There is a weak but statistically significant correlation between PSA and age $(r=$ $0.25 ; P<0.001)$. This is also reflected by the increase in mean PSA in advancing 5 year age-groups (Table II). An equally weak correlation is found between PSA and IPSS ( $\mathrm{r}=0.16 ; P<0.001)$.

PSA and PSAD did not correlate with the body mass index. The correlations between PSAD and age $(r=0.17 ; P<0.001)$ and PSAD and IPSS $(r=0.09 ; P$ $<0.04)$ are both weak. There is a slight increase in mean PSAD in advancing 5 year age-groups (Table II). Calculation of the coefficient of determination shows that only $6 \%$ of the variation in PSA and $3 \%$ of the variation in PSAD, respectively, can be explained by the variation in age.

PSA correlates moderately with VolT $(\mathrm{r}=0.58 ; P$ $<0.001)$ and with VolC $(\mathrm{r}=0.58 ; P<0.001)$. The correlation between PSA and VolP $(r=0.33 ; P<$ 0.001 ) is weaker. Figure 3 shows the scattergram of PSA values versus total prostate volume (VolT).

Using multivariate analysis, it was found that each doubling of VolP, with constant VolC, leads to an average increase of $31 \%(P=0.007)$ of PSA. Each doubling of VolC, with constant VolP, however leads to an average increase of PSA of $108 \%(P<0.001)$. Adjusted for both volume parameters there was no longer any significant correlation between PSA and age $(P=0.22)$.

Figures 4 and 5 show the cumulative frequency of serum PSA levels and PSAD, respectively, in 502 men without prostate cancer and PSA $<10 \mathrm{ng} / \mathrm{ml}$ by International Prostate Symptom Score subgroups. The men were grouped as those with no or minor com-

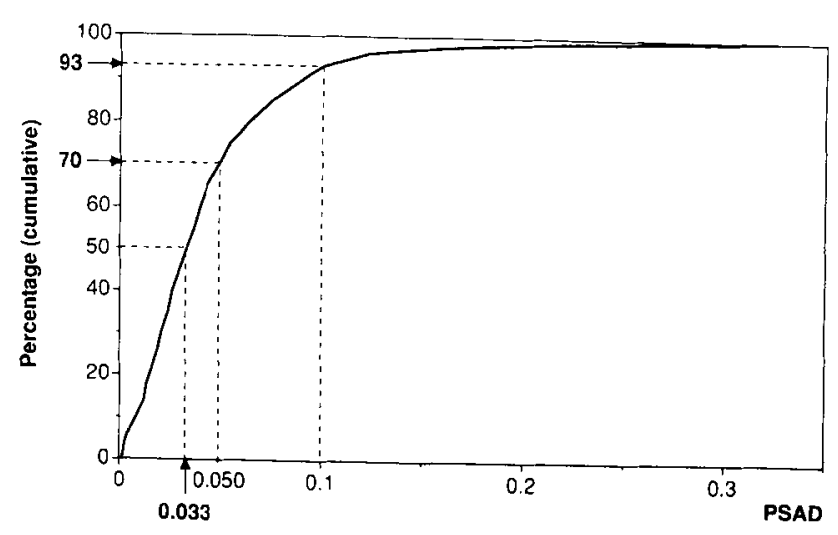

Fig. 2. Cumulative frequency distribution of PSAD values in 502 men without prostate cancer or a previous prostate operation. Men with a serum PSA level above $10 \mathrm{ng} / \mathrm{ml}$ had been excluded.

plaints (IPSS $0-7 ; \mathrm{N}=318$ ), those with moderate complaints (IPSS 8-19; $N=120$ ), and those with severe complaints (IPSS 20-35; $N=30$ ). This grouping by total International Prostate Symptom Scores resulted in significant differences $(P=0.002)$ in median PSA values, whereas the median PSAD did not significantly differ $(P=0.17)$ between IPSS-groups. Further analysis showed that the median PSA value in the group with no or minor complaints $(1.1 \mathrm{ng} / \mathrm{ml})$ differed significantly $(P=0.005)$ from the median value in the group with moderate complaints $(1.3 \mathrm{ng} /$ $\mathrm{ml})$ and also significantly $(P=0.02)$ from the median value in the group with severe complaints $(1.8 \mathrm{ng} /$ $\mathrm{ml})$. The median PSA values in the latter two groups did not differ significantly $(P=0.36)$ from each other. The group of men with severe complaints, however, only consists of 30 men.

\section{DISCUSSION}

The correlations between PSA level and the volume of the central $(r=0.58)$ and peripheral part of the prostate $(r=0.33)$ that were found in this study, support the idea that more PSA is produced in the central (hyperplastic) than in the peripheral part of the prostate. These findings are also in agreement with the fact that elevated PSA levels can be found in men without prostate cancer but with an enlarged prostate due to $\mathrm{BPH}$.

The positive correlation between PSA and age may be due to the fact that prostate volume increases with age. Multivariate analysis indeed showed that age is not an independent factor after adjustment for volume. This is at variance with the results of other studies that found independent effects of age and volume [11-13].

Babaian et al. [11] claimed an independent effect of 
TABLE II. Descriptive Statistics of PSA $(\mathrm{ng} / \mathrm{ml})$ and PSAD Values

$\left(\mathrm{ng} / \mathrm{ml}^{\mathrm{c}} \mathrm{cm}^{3}\right)$ for Consecutive 5 Year Age-Groups of Men Without Prostate Cancer and Without Previous Prostate Operation*

\begin{tabular}{lcccc}
\hline & \multicolumn{4}{c}{ Age (N) } \\
\cline { 2 - 5 } & $55-59(124)$ & $60-64(162)$ & $65-69(132)$ & $70-74(84)$ \\
\hline PSA-value & & & & \\
Mean & 1.2 & 1.5 & 1.8 & 2.4 \\
Median & 0.8 & 1.0 & 1.4 & 1.7 \\
Minimum & $<0.1$ & $<0.1$ & $<0.1$ & $<0.1$ \\
Maximum & 7.9 & 7.3 & 8.4 & 10 \\
SD & 1.3 & 1.5 & 1.6 & 2.2 \\
PSAD-value & & & & \\
Mean & 0.035 & 0.041 & 0.046 & 0.055 \\
Median & 0.030 & 0.029 & 0.038 & 0.043 \\
Minimum & 0.002 & 0.001 & 0.002 & 0.001 \\
Maximum & 0.173 & 0.200 & 0.326 & 0.309 \\
SD & 0.030 & 0.034 & 0.042 & 0.053 \\
\hline
\end{tabular}

${ }^{*}$ Men with a PSA value above $10 \mathrm{ng} / \mathrm{ml}$ had been excluded.

TABLE III. Spearman Correlation Coefficients ( $r$ ) Between PSA or PSAD and Age, IPSS, Body Mass Index, and Between PSA and Prostate Volume Parameters in Men Aged 55-74 Years Without Prostate Cancer and Without Previous Prostate Operation*

\begin{tabular}{lrcc}
\hline Parameters correlated & $\mathrm{r}$ & $\mathrm{r}^{2}$ & $P$-value \\
\hline PSA & & & \\
Body mass index & -0.01 & 0.00 & 0.89 \\
Age & 0.25 & 0.06 & $<0.001$ \\
IPSS & 0.16 & 0.03 & $<0.001$ \\
VolT & 0.58 & 0.34 & $<0.001$ \\
VolC & 0.58 & 0.34 & $<0.001$ \\
VolP & 0.33 & 0.11 & $<0.001$ \\
PSAD & & & \\
Body mass index & -0.07 & 0.00 & 0.10 \\
Age & 0.17 & 0.03 & $<0.001$ \\
IPSS & 0.09 & 0.01 & 0.04 \\
\hline
\end{tabular}

*Men with a PSA value above $10 \mathrm{ng} / \mathrm{ml}$ had been excluded. Coefficient of determination is indicated by $r^{2}$. All correlations are statistically significant except those involving the body mass index.

age and volume with the significance of one not being dependent on the other. The fact that these authors studied men over a wider age range (29-84 years) may be an explanation for this finding. Oesterling et al. [12] found that the serum PSA level was correlated with both age $(\mathrm{r}=0.43 ; P<0.001)$ and prostate volume $(\mathrm{r}=0.55 ; P<0.001)$ and proposed age-specific reference ranges for serum PSA. Their results indi-

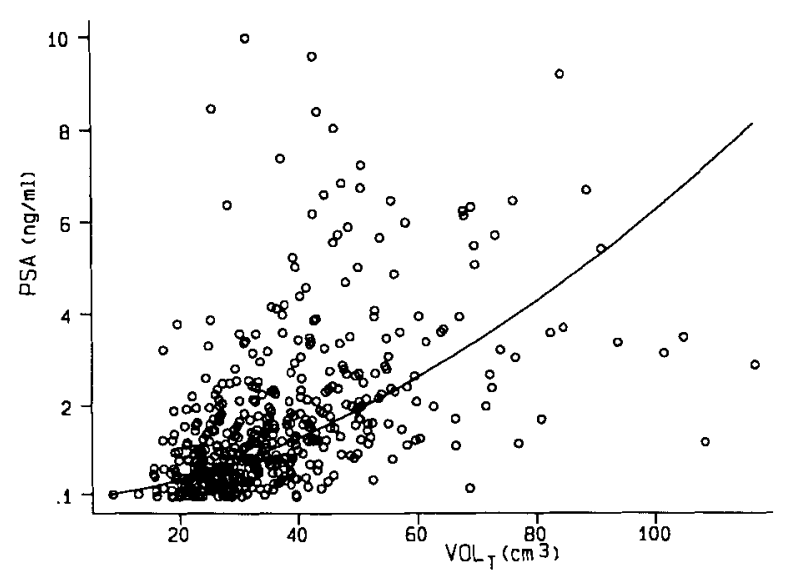

Fig. 3. Scattergram of PSA values $(\mathrm{ng} / \mathrm{ml})$ versus total prostate volume $\left(\right.$ VolT $\left.; \mathrm{cm}^{3}\right)$. Drawn line $[\log (\mathrm{PSA})=-2.61+$ I.70. $\log \left(\right.$ VolT) $\left.; r^{2}=0.30 ; P<0.001\right]$ corresponds to least squares regression line after logarithmic transformation of both axes.

cated that $30 \%$ of the variation in PSA could be attributed to the variation in prostate volume, but that age accounted for an additional $5 \%(P<0.001)$ of the variation in PSA. Their study population was younger, with about half of the 471 men below the age of 55 years, and consequently represented a wider age range (40-79) than the age range in our study population.

Dalkin and associates [21] also determined agespecific reference ranges for men between 50 and 79 years old. Compared to the values determined by Oesterling et al. [12], their reference values were higher for men $60-69$ years old (5.4 as opposed to 4.5 


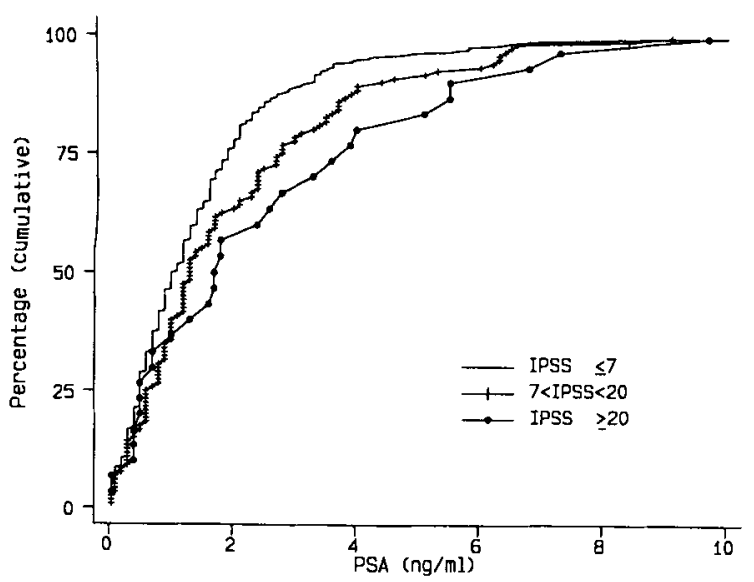

Fig. 4. Cumulative frequency of serum PSA levels in 502 men without prostate cancer or a previous prostate operation by international prostate symptom score-groups. Scores are grouped as no or minor complaints (IPSS $0-7 ; \mathbf{N}=352$ ), moderate complaints (IPSS 8-19; $N=120$ ), and severe complaints (IPSS 20-35; $N=$ 30). Men with a serum PSA level above $10 \mathrm{ng} / \mathrm{ml}$ had been excluded.

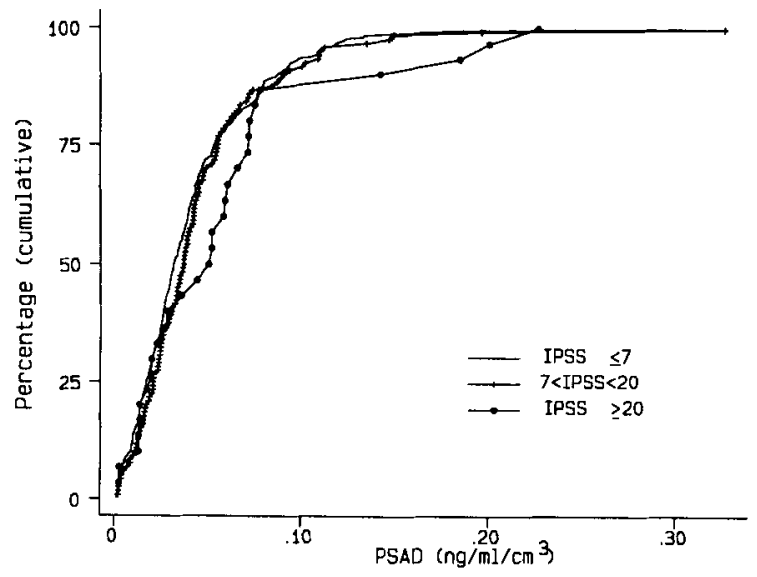

Fig. 5. Cumulative frequency of PSAD values in 502 men without prostate cancer or a previous prostate operation by International Prostate Symptom Score-groups. Scores are grouped as no or minor complaints (IPSS 0-7; $\mathrm{N}=352$ ), moderate complaints (IPSS $8-19 ; N=120$ ), and severe complaints (IPSS 20-35; $N=30$ ). Men with a serum PSA level above $10 \mathrm{ng} / \mathrm{ml}$ had been excluded.

$\mathrm{ng} / \mathrm{ml})$ and lower for men $70-79$ years old (6.3 as opposed to $6.5 \mathrm{ng} / \mathrm{ml}$ ). The men included in the evaluation of Dalkin et al. did not represent a communitybased population but were recruited by advertisements in newspapers.

The percentages of men with a PSA $>4 \mathrm{ng} / \mathrm{ml}$ by age-group in the Olmsted county population [12] can be compared with these percentages in the present population, if the population of men included in the present study is adjusted by the secondary inclusion of half of the 15 men with a PSA $>10 \mathrm{ng} / \mathrm{ml}$ but no prostate cancer: $5.1 \%$ of the men between 55-59 years in the present population and $2 \%$ of the men between $50-59$ in the Olmsted county population have a PSA $>4 \mathrm{ng} / \mathrm{ml}$. The difference is even larger between $60-69$ years with $13 \%$ in Olmsted county as compared to $7.3 \%$ in the present series. The median prostate volumes for the men between 60-69 years in Olmsted county and Rotterdam are comparable ( 34.6 and $33.2 \mathrm{~cm}^{3}$, respectively). It should be noted, however, that prostate volumes were not determined in the men with a PSA $>10 \mathrm{ng} / \mathrm{ml}$ making it impossible to exactly adjust the median prostate volume, but the addition of half of the seven men without prostate cancer and a PSA $>10 \mathrm{ng} / \mathrm{ml}$ between $60-69$ years is unlikely to change the difference between the median prostate volumes very much. Between $70-74$ years we find a percentage of $15.8 \%$ as compared to $19 \%$ for the group of 70-79 years in Olmsted county. Since the biopsy protocol was more liberal in the Olmsted county population, these differences cannot be due to a different percentage of men excluded because of a diagnosis of prostate cancer; if a more liberal biopsy protocol had been employed in our study we would most probably have found some more cancers in the group of men with a PSA $>4 \mathrm{ng} / \mathrm{ml}$. This would have resulted in the exclusion of a few more men with a PSA $>4 \mathrm{ng} / \mathrm{ml}$ from the population of 502 , resulting in an even lower percentage of men with a PSA $>4$ $\mathrm{ng} / \mathrm{ml}$ but without prostate cancer per age stratum.

Collins et al. [13] found a significant and independent correlation between both PSA and age $(r=0.37$; $P<0.001)$ and PSA and total prostate volume $(r=$ $0.56 ; P<0.001$ ) but concluded that "because of the non-linearity of these interrelationships, PSA may be best employed using absolute cut-off levels." Comparing the mean PSA values of the Scottish population and the present population (after correction for the men with PSA $>10 \mathrm{ng} / \mathrm{ml}$ but without prostate cancer as described above) shows that there are again considerable differences by age-group: the mean PSA value between $60-69$ years is $1.8 \mathrm{ng} / \mathrm{ml}$ in the present population as compared to $3.1 \mathrm{ng} / \mathrm{ml}$ in the Scottish study. The mean prostate volume in these two population does not differ for the age-group between $60-69$ years (36 versus $36.5 \mathrm{~cm}^{3}$ ).

Theoretically, the correlation between PSA and age could have been influenced by the exclusion of men with a PSA $>10 \mathrm{ng} / \mathrm{ml}$ but without prostate cancer. If all men would have been included, 15 of the 30 men with a PSA $>10 \mathrm{ng} / \mathrm{ml}$ would have been randomized for screening and consequently half of these (i.e., about seven) would have been free of prostate cancer. Proportionately, one, two, one, and three men with a PSA $>10 \mathrm{ng} / \mathrm{ml}$ would have to be added to the four respective advancing 5 year age- 
groups between 55-74 years. These numbers would have a negligible influence on the correlation between PSA and age.

The lack of an independent correlation between age and PSA indicates that there is a weak basis for the proposal of age-specific reference ranges in the population of men between 55-74 years. Another factor that should be taken into account is the finding that comparative data from Rotterdam, Olmsted County, and Scotland seem to indicate differences in PSA values per age-group despite the use of the same method of serum PSA determination (Hybritech). These differences may be due to population sample biases. To fully understand the reasons for these differences a more detailed epidemiologic analysis would be necessary, including, for example, an analysis of data on types of $\mathrm{BPH}$, incidence of prostatitis, and instrumentation rates. Until such information is available, it is prudent to realize that reference ranges determined for one particular region or country may not necessarily be valid for another area. Furthermore, the proposed age-specific reference ranges have not yet been tested in actual clinical practice.

In the present study, it was found that only $6 \%$ of the variation in PSA can be attributed to the variation in age. However, $34 \%$ of the variation in PSA can be attributed to the variation in volume.

The correlation coefficient between PSA and total prostate volume observed in the present study $(r=$ 0.58 ) is almost identical to the data presented by Oesterling et al. [12] $(\mathrm{r}=0.55)$ and by Collins et al. [13] $(r=0.56)$. The correlation coefficients between PSA and age show considerable differences: $r=0.25$ in the present study and $r=0.37$ and $r=0.43$ in the studies reported by Collins et al. [13] and Oesterling et al. [12], respectively. The major difference between these studies is the age range of men included, which was $55-74$ years in the present study and $40-79$ years in both other studies. It would be interesting to study the correlation coefficient between age and PSA in both other samples of men after exclusion of those who are not between 55-74 years of age. This may be important because the main target age-range for prostate cancer screening does not include men between 40-55 years of age unless a heriditary factor is suspected: only $2 \%$ of all prostate cancers in American white men occur in those 55 years or younger, whereas the heriditary form of prostate cancer accounts for $43 \%$ of the cases with an onset below 55 years of age [22].

Based on the fact that there is a positive correlation between PSA values and volume, the idea of defining reference values for different volume classes or to adjust PSA for volume has been introduced $[9,10]$. The correlation coefficient between PSA and total volume in the present study, however, is only moderate. Furthermore, only $34 \%$ of the variation in PSA is explained by the variation in volume of the central part of the gland. These results do not support the usefulness in clinical routine and screening programs of PSA reference values for different volume classes, even if the volumes of the central or peripheral part of the gland are considered specifically.

Of the men in the present study, only $2 \%$ had a PSAD greater than 0.15 , whereas $97.5 \%$ had a PSAD below 0.145. In their original article on PSAD, Benson et al. [9] found that none of their $20 \mathrm{BPH}$ patients had a PSAD value above 0.117 . In the present study, 95\% of the men had a PSAD below 0.117.

Interesting is the finding that although PSA does not correlate independently with age (i.e., after adjustment for volume), PSAD still correlates ( $r=0.17$; $P<0.001$ ) with age. Since prostate volume is also positively correlated with age $(\mathrm{r}=0.26 ; P<0.001)$, a possible explanation for this finding may be that PSAD provides an incomplete volume adjustment. Indeed, the correlation between PSAD and total prostate volume in this study amounts to $\mathrm{r}=0.26(P<$ 0.001 ), which proves that PSAD does not provide a full volume adjustment. An alternative explanation for the correlation between PSAD and age, could be the possible influence with increasing age of other factors than volume, such as elements of prostatitis or infarction. If this were true, one could reason that men with prostatitis or infarction would possibly be more symptomatic and that, consequently, PSAD values might differ significantly between IPSS groups. This is, however, not the case. Statistical analysis shows that although median PSA values differ significantly between IPSS groups $(P=0.002)$ there is no significant difference of median PSAD values between IPSS groups $(P=0.17)$ (see Fig. 5). Other factors that frustrate prostate volume correction of serum PSA levels are the findings recently reported by Mandell et al. [23]. They found marked variations in stromal to epithelial ratios in $\mathrm{BPH}$ patients and an absence of correlation between PSAD and grams of epithelium, and stromal to epithelial ratio. They also found an age dependent decrease in PSA production per gram of epithelium.

\section{SUMMARY}

1. Prostate volume adjustment with the intention to increase the specificity of serum PSA values in the detection of prostate cancer has been proposed either with specific volume ranges or with the use of PSAD. The moderate correlations between PSA and prostate volume parameters and the incomplete volume adjustment that is provided by the use of PSAD, do not 
support the clinical usefulness of PSA reference values for different volume classes, even if the volumes of the central or peripheral part of the gland are considered specifically.

2. Age specific reference ranges for serum PSA values have been proposed for use in screening for prostate cancer. The lack of an independent correlation between age and PSA in the present study does not support the clinical usefulness of this approach in men between $55-74$ years old.

3 . There may be significant regional differences in PSA values per age-group. Further studies are needed to clarify the reasons for these differences.

4. The positive correlation between PSAD and age can be explained in part by the incomplete volume adjustment of PSAD. An increase with age of prostatic abnormalities such as prostatitis or infarctions, could be an alternative explanation. The present study does not support this latter possibility since there is no significant difference in PSAD between groups of men with different levels of symptom severity.

5. There is no correlation between PSA or PSAD and body mass index.

\section{REFERENCES}

1. Nadji M, Tabei SZ, Castro A, Chu TM, Murphy GP, Wang MC, Morales AR: Prostate-specific antigen: an immunohistologic marker for prostatic neoplasms. Cancer 48:1229-1232, 1981.

2. Oesterling JE, Chan DW, Epstein JI, Kimball AW, Bruzek DJ, Rock RC, Brendler CB, Walsh PC: Prostate specific antigen in the preoperative and postoperative evaluation of localized prostate cancer treated with radical prostatectomy. J Urol 139:766-772, 1988.

3. Armitage TG, Cooper $\mathrm{EH}_{\text {r }}$ Newling WW, Robinson MRG, Appleyard I: The value of the measurement of prostate specific antigen in patients with benign prostatic hyperplasia and untreated prostate cancer. $\mathrm{Br} \mathbf{J}$ Urol 62:584-589, 1988.

4. Ercole CJ, Lange PH, Mathisen M, Chiou RK, Reddy PK, Vesella RL: Prostate specific antigen and prostatic acid phosphatase in the monitoring and staging of patients with prostatic cancer. J Urol 138:1181-1184, 1987.

5. Hudson MA, Bahnson RR, Catalona WJ: Clinical use of prostate specific antigen in patients with prostate cancer. J Urol 142:1011-1017, 1989.

6. Stamey TA, Yang N, Hay AR, McNeal JE, Freiha FS, Redwine E: Prostate-specific antigen as a serum marker for adenocarcinoma of the prostate. N Eng J Med 317: 909-916, 1987.

7. Weber JP, Oesterling JE, Peters CA, Partin AW, Chan DW, Walsh PC: The influence of reversible androgen deprivation on serum prostate-specific antigen levels in men with benign prostatic hyperplasia. J Urol 141:987992, 1989.

8. Partin AW, Carter HB, Chan DW, Epstein JI, Oesterling JE, Rock RC, Weber JP, Walsh PC: Prostate specific an- tigen in the staging of localized prostate cancer: influence of tumor differentiation, tumor volume and benign hyperplasia. J Urol 143:747-752, 1990.

9. Benson MC, Whang IS, Pantuck A, Ring K, Kaplan SA, Olsson CA, Cooner WH: Prostate specific antigen density: a means of distinguishing benign prostatic hypertrophy and prostate cancer. J Urol 147:815-816, 1992.

10. Kane RA, Littrup PJ, Babaian R, Drago JR, Lee F, Chesley A, Murphy GP, Mettlin C, investigators of the American Cancer Society National Prostate Cancer Detection Project: Prostate-specific antigen levels in 1695 men without evidence of prostate cancer. Cancer 69: 1201-1207, 1992.

11. Babaian RJ, Miyashita H, Evans RB, Ramirez EI: The distribution of prostate specific antigen in men without clinical or pathological evidence of prostate cancer: relationship to gland volume and age. J Urol 147:837-840, 1992.

12. Oesterling JE, Jacobsen SJ, Chute CG, Guess HA, Girman CJ, Panser LA, Lieber MM: Serum prostate-specific antigen in a community-based population of healthy men. JAMA 270:860-864, 1993.

13. Collins GN, Lee RJ, McKelvie GB, Rogers ACN, Hehir M: Relationship between prostate specific antigen, prostate volume and age in the benign prostate. $\mathrm{Br} \mathrm{J}$ Urol 71:445-450, 1993.

14. Bosch JLHR, Niemer AQHL, Kirkels WJ, Schröder FH: Signs and symptoms of benign prostatic hyperplasia in men screened for prostatic carcinoma. In Kurth $\mathrm{KH}$, Newling DWW (eds): "Benign Prostatic Hyperplasia: Recent Progress in Clinical Research and Practice." EORTC Genitourinary Group Monograph 12. New York: Wiley-Liss, 1994, pp 97-107.

15. Mebust W, Roizo R, Schroeder F, Villers A: Correlations between pathology, clinical symptoms and the course of the disease. In Cockett ATK, Aso Y, Chatelain C, Denis L, Griffiths K, Khoury S, Murphy G (eds): "Proceedings of the International Consultation on Benign Prostatic Hyperplasia." Chapter 3. Geneva: WHO, 1991, pp 51-62.

16. Catalona WJ, Smith DS, Ratliff TL, Dodds KM, Coplen DE, Yuan JJJ, Petros JA, Andriole GL: Measurement of prostate-specific antigen in serum as a screening test for prostate cancer. N Eng J Med 324:1156-1161, 1991.

17. Barry MJ, Fowler FJ, O'Leary MP, Bruskewitz RC, Holtgrewe HL, Mebust WK, Cockett ATK, the measurement committee of the American Urological Association: The American Urological Association symptom index for benign prostatic hyperplasia. J Urol 148:15491557, 1992.

18. Jakobsen $H$, Torp-Pedersen $S$, Juul N: Ultrasonic evaluation of age-related human prostatic growth and development of benign prostatic hyperplasia. Scand J Urol Nephrol [suppl] 107:26-31, 1988.

19. Davidson PJ, Niemer QH, Schröder FH: Prostate volume measurement with the $7 \mathrm{MHz}$ transrectal probe. Br J Urol 71:73-74, 1993.

20. MCNeal JE: Origin and evolution of benign prostatic enlargement. Invest Urol 15:340-345, 1978.

21. Dalkin BL, Ahmann FR, Kopp JB: Prostate specific antigen levels in men older than 50 years without clinical evidence of prostatic carcinoma. J Urol 150:1837-1839, 1993.

22. Carter BS, Bova GS, Beaty TH, Steinberg GD, Childs B, Isaacs WB, Walsh PC: Heriditary prostate cancer: epi- 
demiologic and clinical features. J Urol 150:797-802, 1993.

23. Mandell K, Partin A, Hill G, Epstein J, Stutzman R,
Ballentine Carter $\mathrm{H}$, Walsh P: PSA density in BPH: correlation with stromal epithelial ratios and influence of age. J Urol 149:448A, 1993. 